\title{
Structure, condition, and prospects of electrical grids in the Republic of Sakha (Yakutia)
}

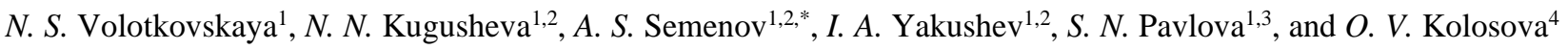 \\ ${ }^{1}$ North-Eastern Federal University n.a. M.K. Ammosov, Polytechnic Institute (branch) in Mirny, Sakha (Yakutia), Russia \\ ${ }^{2}$ North-Eastern Federal University n.a. M.K. Ammosov, Institute of Mathematics and Information Science, Sakha (Yakutia), Russia \\ ${ }^{3}$ North-Eastern Federal University n.a. M.K. Ammosov, Institute of Finances and Economics, Sakha (Yakutia), Russia \\ ${ }^{4}$ Peter the Great St. Petersburg Polytechnic University, St Petersburg, Russia
}

\begin{abstract}
The paper analyzes the condition of electrical grids in the west of the Republic of Sakha (Yakutia); data sampled for the last 10 years. It demonstrates the geographic location of grids, which defines the scale of the study. Technical indicators are presented for 10 years; they reflect an increase in the fixed assets. The paper derives mathematical models of the wear of transmission equipment used in the western grids. It proves that the condition of equipment will deteriorate further unless its maintenance is properly funded. The paper analyzes the prospects of electrical grids in the Republic of Sakha (Yakutia). It presents a program for local energy optimization. The costs associated with five alternative development scenarios are calculated and presented in a tabular format.
\end{abstract}

\section{Introduction}

Improving the reliability of electric power systems is one of the key challenges for the modern power engineering. Whether it could be successfully addressed depends on the operator being able to properly organize timely maintenance and repairs, use of appropriate decisionmaking methods to decide when system-wide maintenance is necessary [1]. This requires comprehensive studies into normal and emergency operation of grids, as well as measures to ensure smooth and reliable operation of such grids [2].

Maintenance optimization, repairs, and diagnostics of electric grids in the North were studied by Yu.Z. Kovalyova, B.G. Menshova, M.S. Yershova, V.V. Sushkova, V.P. Frolova et al [3].

Widespread use of electric power in various technological processes means that nowadays manufacturing depends ever more on reliable power supply [4, 5]. Emergencies and unscheduled outages, especially in winter or in permafrost, are likely to disrupt the process, damage the equipment, cause a loss of product or money, and lead to occupational injuries and fatalities [6].

This is why it is increasingly relevant to study the structure and condition of power transmission equipment [7].

Yakutia's electric power industry is nowadays mainly built upon power plants and grids operated by PAO Yakutskenergo with a total installed capacity of $2143 \mathrm{MW}$; those produce $96-97 \%$ of the total power and
$30 \%$ of the total heat in the Republic. HPPs account for $37.5 \%$ of the installed capacity. Centralized power supply is now available in about $36 \%$ of the Republic territory, or 18 out of 35 administrative entities, which account for $>85 \%$ of the population. Four large power districts are isolated form each other capacity-wise: Central, Western, Southern, and Northern. PAO Yakutskenergo grids cover a total of 3.2 million sq.km.

The Western Power District mainly draws power from the HPPs located by the Vilyuy River: Vilyuyskaya HPP (Cascades 1 and 2), 680 MW of installed capacity; and Svetlinskaya HPP, $180 \mathrm{MW}$ of installed capacity. Some settlements contain dozens of smaller diesel-fueled power plants (diesel gensets) that belong to different institutions and distribute electricity in a $0.4-$ to $35-\mathrm{kV}$ range; these operate in isolation.

\section{Object of research}

Western Electric Grids (WEG) provide power to consumers in the Western Power District, Republic of Sakha (Yakutia), including Mirninsky District, Lensky District, Vilyuysk District Group (Suntarsky, Nyurbinsky, Verkhnevilyusky, Vilyuysky, and part of Kobyasky Districts). OPL L-242 connects Suntar to Olekminsk, which is located in the South-Yakut Power District, while a double-circuit 220-kV OPL connects the Talakanskaya TPP in the south of the Republic to the Irkutsk grids. WEG also includes backup diesel gensets located in Nyurba, Vilyuysk, Verkhnevilyuysk.

\footnotetext{
*Corresponding author: as.semenov@s-vfu.ru
} 
Table 1. Grid indicators over 10 years [9].

\begin{tabular}{|c|c|c|c|c|}
\hline \multicolumn{1}{|l|}{ Ino } & Indicator & Unit & $\begin{array}{c}\text { It was on balance } \\
(\mathbf{0 1 / 0 1 / 2 0 0 8 )}\end{array}$ & $\begin{array}{c}\text { On balance } \\
(\mathbf{0 1 / 0 1 / 2 0 1 8 )}\end{array}$ \\
\hline 1 & The total length of the lines, including: & $\mathrm{km}$ & 7607 & 8729 \\
\hline 1.1 & $220 \mathrm{kV}$ & $\mathrm{km}$ & 1344 & 1149 \\
\hline 1.2 & $110 \mathrm{kV}$ & $\mathrm{km}$ & 1517 & 1531 \\
\hline 1.3 & $35 \mathrm{kV}$ & $\mathrm{km}$ & 1325 & 1437 \\
\hline 1.4 & $10 \mathrm{kV}$ & $\mathrm{km}$ & 1715 & 2104 \\
\hline 1.5 & $6 \mathrm{kV}$ & $\mathrm{km}$ & 279 & 374 \\
\hline 1.6 & $0.4 \mathrm{kV}$ & $\mathrm{km}$ & 1427 & 2134 \\
\hline 2 & Total number and capacity of substations, \\
including: & pcs./MVA & $88 / 2765$ & $92 / 2790$ \\
\hline 2.1 & $220 \mathrm{kV}$ & pcs./MVA & $5 / 1031$ & $5 / 1015$ \\
\hline 2.2 & $110 \mathrm{kV}$ & pcs./MVA & $43 / 1500$ & $38 / 1522$ \\
\hline 2.3 & 35 kV & pcs./MVA & $40 / 234$ & $49 / 253$ \\
\hline 3 & The total number and capacity of transformers, & pcs./MVA & $1037 / 318$ & $1447 / 444$ \\
\hline 3.1 & including: & pcs./MVA & $994 / 241$ & $1300 / 336$ \\
\hline 3.2 & complete & pcs./MVA & $43 / 77$ & $123 / 105$ \\
\hline 3.3 & closed & pcs./MVA & - & $24 / 3$ \\
\hline
\end{tabular}

The major consumers are the diamond industry and the oil-pumping stations. Note that the oil refining and gas production in Western Yakutia have been on the rise over the past 10 years. The largest consumers are: the oil-refining stations NPS-11,12,13,14 as well as PAO AK ALROSA factories: Mirninsky, Aikhalsky, and Udachinsky Mining and Processing Complexes [8]. Besides, the compressor stations CS-1 and CS-2 will be connected after the Power of Siberia gas line is complete and launched.

Total WEG coverage exceeds $800 \mathrm{~km}$. Distance from the distribution grid bases to the most remote users may exceed $100 \mathrm{~km}$ despite the standard-specified optimum of $40 \mathrm{~km}$.

Table 1 presents the data on the changes in the WEG indicators over ten years (2008-2018).

As of January 1, 2018, WEG operated 92 35- to 220$\mathrm{kV}$ stepdown substations (SS), 2790 MVA of total installed capacity; 1447 6-10/0.4-kV TS, 444 MVA of total installed capacity; and $8729 \mathrm{~km}$ of $0.4-$ to $220-\mathrm{kV}$ overhead power lines (OPL). Ten years ago [10], i.e. as of January 1, 2008, WEG operated 88 SS (2765 MVA), 1037 TS (318 MVA), and $7607 \mathrm{~km}$ of OPL (same voltage categories).

Figure shows the geographical location of the Western Power District and its 220-110-kV OPL and basic TS; solid green lines for 220-kV OPL; solid black lines for $110-\mathrm{kV}$ OPL; dashed green lines for $110-$ to 220-kV planned OPL.

\section{Problem statement}

The use of current state-of-the-art technologies of the West Siberian industries is likely to bolster the indicators of the Western Electric Grids: they will see an increase in the number and capacity of substations at various voltage levels, as well as in the total length of power transmission lines [11].

Analysis of outages attributable to faulty power equipment operated by PAO Yakutskenergo shows that maintenance errors cause $4 \%$ of outages; defective installations and adjustments cause $3 \%$ of outages; erroneous design or structure cause $1 \%$ of outages; aging equipment and insulation wear cause $31 \%$ of outages; atmospheric and natural phenomena cause $28 \%$ of outages; third parties cause $16 \%$ of outages; $17 \%$ of outages happen for other reasons.

When planning repairs and retrofitting of grid equipment, the WEG take considerable effort to diagnose and visually inspect the equipment [12]. To determine the repair methods and deadlines, all the equipment is separated by the condition factor (\% wear) into five groups, ranging from the Good Condition (20\% wear) to Critical ( $>80 \%$ wear) [13].

Condition Index is calculated to determine the operating condition of the WEG-operated fixed assets. The index is calculated using a special method per draft Order of the Ministry of Energy [14]. Equipment wear (shown as \%) is an inverse of the Condition Index; it is used to group the equipment to determine repair methods and deadlines.

Like the entirety of PAO Yakutskenergo, WEG OPL are mainly supported by wooden pylons; the percentages are as follows: wooden pylons account for $92 \%$; metal pylons account for 7\%; reinforced-concrete pylons account for $1 \%$.

Based on the processing, analysis, and generalization of PAO Yakutskenergo grid statistics, the specific OPL failure rate per $\mathrm{km}$ a year is: $3 \%$ for wooden pylons; $13 \%$ for reinforced-concrete pylons; $10 \%$ for metal-tube pylons.

Given that the pylon service life is maxed out at 25 to 30 years, $80 \%$ wear is allowable for $7 \%$ to $10 \%$ of 
wooden pylons in $35-$ to $220-\mathrm{kV}$ mainline grids, or for $10 \%$ to $12 \%$ of pylons in 6 - to $10 / 0.4-\mathrm{kV}$ distribution grids at max. However, state-of-the-art analysis shows that such $220-\mathrm{kV}$ lines as L-203, 204, 206, or $110-\mathrm{kV}$ lines such as L-108, 109, 117, 119 are operated in a "deteriorated condition"; OPL and substation equipment deteriorate more and more every year [15].

\section{Research methodology}

To describe the dynamics of WEG power equipment wear, the researchers developed mathematical models based on the time-to-failure distribution and used MatLab for calculations and approximation of the empirical functions.

Choosing a distribution law is by and large an indefinite and subjective procedure, which largely depends on the a priori knowledge of the object, its properties and operating conditions. Apparently, which distribution will be chosen depends primarily on the empirical failure distribution density function $\mathrm{f}(\mathrm{t})$ as well as on the failure rate function $\lambda(t)$. Exponential distribution is commonly used for assessing the reliability of power facilities. However, this paper is devoted to the "aging" facilities. This is why the research team has chosen the log-normal distribution, which describes the time-to-failure in such facilities where failure is attributable to fatigue [16, 17].

If the value $\lg (\mathrm{t})$ is normally distributed with the mathematical expectation $\mathrm{U}$ and standard deviation $\mathrm{V}$, the value $\mathrm{T}$ is deemed to have a log-normal distribution, where the failure distribution density is as follows:

$$
f(t)=\frac{1}{V \cdot t \sqrt{2 \pi}} \cdot e^{\left(-\frac{\lg (t)-U^{2}}{2 V^{2}}\right)} .
$$

$\mathrm{U}$ and $\mathrm{V}$ can be approximated using the statistical data:

$$
U \approx \frac{1}{N} \cdot \sum_{1}^{N} \lg \left(t_{i}\right), \quad V \approx \frac{1}{N-1} \cdot \sum_{1}^{N}\left(\lg \left(t_{i}\right)-U\right)^{2}
$$

Numeric characteristics such as mean time to failure and its variance will therefore equal:

$$
T_{0}=e^{\left(U+\frac{V^{2}}{2}\right)}, \quad D=e^{\left(2 U+V^{2}\right)} \cdot\left(e^{\left.V^{2}-1\right)} .\right.
$$

This distribution law was applied to the statistical data on the WEG power equipment condition over the last 5 years (2013-2017). Calculations were run in MatLab, a tool proven useful for mathematical and engineering calculations $[18,19]$.

\section{Research results}

Source data for mathematical modeling is shown in Figure 1, which presents the increase in the WEG fixed assets wear over 2013-2017. While the overall wear of fixed assets fluctuates, as those are partially retrofitted or overhauled, the OPL and SS equipment wear is only increasing [20, 21].

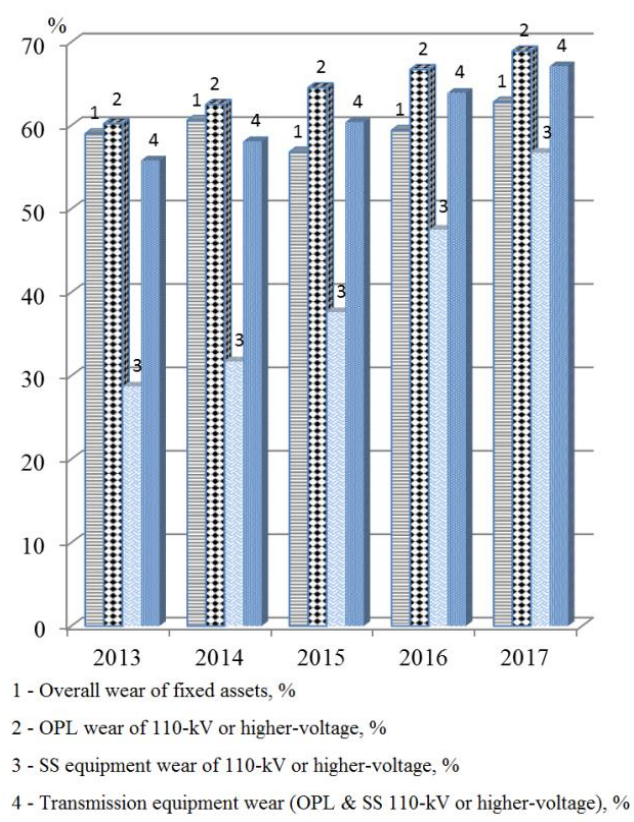

Fig. 1. Fixed assets wear.

MatLab was used to analyze the data and derive three mathematical models (approximated functions) to describe the dynamics of OPL, SS, and transmission equipment wear; three of the functions feature linear dependency while one has a polynomial dependency. For linear dependencies, $\mathrm{MO}$ and $\mathrm{CKO}$ equal, respectively: for OPL: $\mathrm{y}=2.16 \mathrm{x}+58.08$; $\mathrm{R} 2=0.9997$; for transmission equipment: $y=2.84 x+52.54 ; \quad R 2=0.9907$. For the polynomial dependency of substation equipment wear, MO and SKO are defined as follows: $y=-0.3 x^{3}+3.8714 x^{2}-6.9286 x+32 ; R 2=0.9991$.

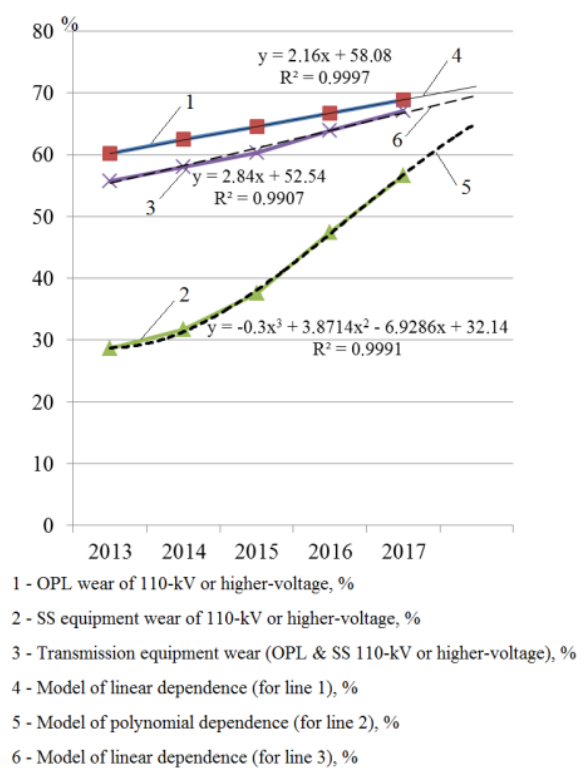

Fig. 2. Mathematical models of power equipment wear dynamics. 
Table 2. Local Energy Optimization Program.

\begin{tabular}{|c|c|c|}
\hline № & Scenario & Indicator \\
\hline 1 & Greater backup & $\begin{array}{c}\text { Determine the installed capacity of generating facilities as is conventional: the installed capacity } \\
\text { must be 150\% to 350\% of the peak consumer load }\end{array}$ \\
\hline 2 & Moderate backup & $\begin{array}{c}\text { Installed power of new generating facilities depends on the feasibility of installing similar units (4 } \\
\text { in operation and 2 for backup): the installed capacity must be about 150\% of the peak consumer } \\
\text { load }\end{array}$ \\
\hline 3 & Grids & $\begin{array}{c}\text { Consider the efficient designs for laying electrical grids to remote settlements. Actions at } \\
\text { generating facilities in the remaining municipalities are taken based on the most efficient Scenario } \\
1 \text { or Scenario 2 solution }\end{array}$ \\
\hline 5 & $\begin{array}{c}\text { High proportion of } \\
\text { renewable energy }\end{array}$ & $\begin{array}{c}\text { Determine the installed capacity of generating facilities as is conventional: the installed capacity } \\
\text { must be 150\% to 350\% of the peak consumer load. Additionally, construct renewable energy } \\
\text { facilities to further reduce the economically sound electricity tariffs }\end{array}$ \\
\hline
\end{tabular}

The presented mathematical models (Figure 2) show positive dynamics in the wear of fixed assets. Annual average increase in wear is: $2.2 \%$ for $110-\mathrm{kV}$ or highervoltage OPL; $6.3 \%$ for $110-\mathrm{kV}$ or higher-voltage SS equipment.

The obtained mathematical models indicate that the probability of WEG increase in wear is 95\% [22-25].

The problem was discussed as part of the agenda for State Council Presidium Meeting No. 2288 dd. May 03, 2015; the meeting resolutions included an order to draft a Long-Term Local Energy Optimization Program (LEOP). The Program is mainly aimed at:

1. Providing high-quality reliable power supply to remote settlements [26];

2. Reducing the subsidies to the local electric power industry in the Republic of Sakha (Yakutia);

3. Upgrading the fixed assets that are in poor condition.

For each generating facility, the LEOP considers several retrofitting options: replacement with diesel units; replacement with oil units; replacement with gas units (mainline gas or liquefied hydrocarbon gas); use of renewable energy (wind and solar farms) [27, 28]; assigning a generating facility to the backup set and using power transmission lines only; establishment of regional power systems, power consolidation and advancement of the power grid complex.

Analysis into these options has produced a list and a schedule of actions that must be taken at local generating facilities while reporting the indicators that describe the technological and cost effectiveness [29, 30]. Thus, the LEOP provides 5 alternative scenarios, see Table 2 .

All the scenarios are aimed at reducing the economically sound electricity tariffs while reducing the subsidies to the local generation facilities. Table 3 compares these scenarios economically.

All the scenarios imply an increase in the oil consumption at AO Sakhaenergo generation facilities. AO Sakhaneftegazsbyt infrastructure and backups will need an upgrade. Upgrade will cost approximately 203 million rubles in 2016 prices (without VAT). These costs are not included in the LEOP and require further clarification.

\section{Conclusion}

The authors have analyzed the condition of power equipment operated by the Western Electrical Grids. The paper presents 5-year statistics on OPL, SS equipment, and WEG transmission equipment wear. Mathematical

Table 3. LEOP scenario comparison (excluding compensations for increased tariff burden and subsidies to central-power users).

\begin{tabular}{|c|c|c|c|c|c|c|}
\hline № & Technical indicators as a result of the implementation & \multicolumn{5}{|c|}{ Scenario } \\
\cline { 4 - 7 } & \begin{tabular}{c} 
scenarios \\
\cline { 3 - 7 }
\end{tabular} & $\mathbf{1}$ & $\mathbf{2}$ & $\mathbf{3}$ & $\mathbf{4}$ & $\mathbf{5}$ \\
\hline 1 & Installed capacity of new generation facilities, MW & 108.7 & 81.4 & 82.3 & 145.8 & 126.6 \\
\hline 2 & Total capital investments, billion rubles & 13.06 & 11.95 & 29.29 & 20.8 & 36.98 \\
\hline 3 & The total effect for 2017-2040 (reduction of cross-subsidies), \\
billion rubles & 21.8 & 22.5 & 36.6 & 25.0 & 38.9 \\
\hline 4 & The ratio of the total effect for 2017-2040 to capital investments & 1.67 & 1.88 & 1.25 & 1.2 & 1.05 \\
\hline 5 & Reducing the economically viable electricity tariff, \% & 13.9 & 14.4 & 16 & 17.3 & 18.8 \\
\hline 6 & $\begin{array}{c}\text { Total investment subsidies and cross-subsidies for local energy in } \\
\text { the period 2017-2040, billion rubles }\end{array}$ & 161 & 159.2 & 162.5 & 165.6 & 167.8 \\
\hline 7 & $\begin{array}{c}\text { Efficiency in electricity production at JSC Sakhaenergo facilities, } \\
\text { \% }\end{array}$ & 34 & 34 & 34 & 39.2 & 39.0 \\
\hline 8 & $\begin{array}{c}\text { Reducing the amount of imported diesel fuel for local power } \\
\text { generation facilities, \% }\end{array}$ & 44 & 44 & 50 & 58 & 63 \\
\hline
\end{tabular}


models have been constructed to describe the positive dynamics of power equipment wear.

The current OPL and SS (110-kV or higher) maintenance and repair budget of the WEG branch, PAO Yakutskenergo, cannot enable timely recovery of power transmission equipment or any reduction in the wear of fixed assets. Considering the effective electricity tariffs, higher maintenance and repair expenses are not an option.

The analyzed Local Energy Optimization Program of the Republic of Sakha (Yakutia) will definitely help to improve the reliability and fail-safety of individual WEG elements (SS and OPL); however, lack of repair and restoration of WEG fixed assets will likely result in 95\% of the $110-\mathrm{kV}$ substation equipment failing by 2023 .

\section{References}

[1] V.G. Kitushin, E.V. Ivanova, Problemy Upravleniya 5, 46 (2011)

[2] V.V. Khudyakov, Russian Electrical Engineering 82455 DOI: 10.3103/S1068371211090070

[3] T.D. Basyrova, V.V. Sushkov, P.S. Plyuhin, Problemy ehlektrotekhniki, ehlektroehnergetiki $i$ ehlektrotekhnologii 19 (2011)

[4] V.I. Zatsepina, E.P. Zatsepin, Int. Conf. on Industrial Engineering, Applications and Manufacturing (ICIEAM) DOI: 10.1109/ICIEAM.2017.8076218 (2017)

[5] A.N. Shpiganovich, V.I. Zatsepina, A.A. Shpiganovich, V.M. Stepanov, EAI Endorsed Transactions on Energy Web 18 e10 DOI: 10.4108/eai.10-7-2018.155083

[6] D. Krongauz, Eh. Electric Power. Transmission and Distribution 6, 54 (2017)

[7] E.I. Gracheva, R.R. Sadykov, Proceedings of the higher educational institutions. Energy sector problems 19, 95 (2017)

[8] A.S. Semenov, N.M. Kuznetsov, Measurement Techniques 57417 DOI: 10.1007/s11018014-0470-8 (2014)

[9] G.A. Ryazanceva, N.G. Efremov, N.S. Volotkovskaya, Student Scientific Forum http://www.scienceforum.ru/2018/3000/4437 (2018)

[10] N.S. Volotkovskaya, 2006 Bulletin of Yakutsk State University 3, 52 (2006)

[11] N.S. Volotkovskaya, A.S. Semenov, O.V. Fedorov, Proceedings of the higher educational institutions. Energy sector problems 20, 46 DOI: 10.30724/1998-9903-2018-20-11-12-46-55 (2018)

[12] G.M. Mikheev, T.G. Ivanova, D.I. Konstantinov, A.K. Turdiev Russian Electrical Engineering 88, 423 DOI: 10.3103/S1068371217070112 (2017)

[13] G.M. Mikheev, T.G. Ivanova, K.U. Kalandarov, A.K. Turdiev, Power Technology and Engineering 50, 213 DOI: 10.1007/s10749-016-0686-7 (2016)

[14] Order of the Ministry of Energy of the Russian Federation dated July 26, No. 676 "On approval of the methodology for assessing the technical condition of the main process equipment and transmission lines of electrical complexes of power plants" registered in the Ministry of Justice of the Russian Federation October 5, 48429 (2017)

[15] E.I. Gracheva, O.V. Naumov, R.R. Sadykov 2016 Proceedings of the higher educational institutions. Energy sector problems 1-2, 53

[16] Yu.K. Belyaev, V.A. Bogatyrev, V.V. Bolotin and oth. Reliability of technical systems: reference book (Moscow: Radio and Communication) p 608 (1985)

[17] B.V. Gnedenko, Yu.K. Belyaev, A.D. Solov'ev Mathematical methods in reliability theory (Moscow: Nauka) 524 (1965)

[18] A.S. Semenov, I.A. Yakushev, A.N. Egorov, Modern high technologies 8, 56 DOI: 10.17513/snt.36780 (2017)

[19] A.S. Semenov, V.M. Khubieva, Y.S Kharitonov, Int. Russian Automation Conf (RusAutoCon)

10.1109/RUSAUTOCON.2018.8501666 (2018)

[20] E.I. Gracheva, A.R. Safin, R.R. Sadykov Safety \& Reliability of Power Industry 10, 48 (2017)

[21] I.V. Bryakin, I.V. Bochkarev, V.R. Khramshin, Int. Russian Automation Conf. (RusAutoCon) DOI: 10.1109/RUSAUTOCON.2018.8501787 (2018)

[22] A. Malafeev, A. Iuldasheva, Procedia Engineering 129, 433 DOI: 10.1016/j.proeng.2015.12.145 (2015)

[23] M.M. Rao, M.J. Thomas, B.P. Singh , IEEE Transactions on Power Delivery 22, 1505 DOI: 10.1109/TPWRD.2007.901292 (2007)

[24] M. Roser, G. Stumberger, International Journal of Electrical Power \& Energy Systems 64, 714 DOI: 10.1016/j.ijepes.2014.07.068 (2015)

[25] D.A. Ustinov, S.V. Baburin, International Journal of Applied Engineering Research 11, 6402 (2016)

[26] Y.V. Shevyrev, O.V. Fedorov, A.S. Sarvarov, Mining Informational and Analytical Bulletin 3, 82 DOI: 10.25018/0236-1493-2018-3-0-82-90 (2018)

[27] O.E. Konovalova, N.M. Kuznetsov, Industrial power engineering 9, 51 (2018)

[28] A.S. Semenov, V.S. Shipulin, E.I. Rushkin, P.V. Savvinov, R.E. Eremeeva, International Scientific Journal for Alternative Energy and Ecology 2138 (2013)

[29] N.E. Egorov, G.S. Kovrov, S.N. Pavlova, Innovations 11, 73 (2018)

[30] S.N. Pavlova, I.V. Lugovkin, Problems of modern economics 4, 424 (2012) 